\title{
Reforma a
}

telecomunicaciones y

radiodifusión en México:

la perspectiva de la

Asociación Mexicana

del Derecho a la

Información* / Reform

of Telecommunications

and Broadcasting in

Mexico: The Perspective

of the Mexican

Association of the Right to Information

* Recibido: 18 de marzo de 2015. Aceptado: 21 de abril de 2015.

Tla-Melaua, revista de Ciencias Sociales. Facultad de Derecho y Ciencias Sociales. Benemérita Universidad Autónoma de Puebla, México / IssN: 1870-6916 / Nueva Época, Año 9, No 39, octubre 2015/marzo 2016, pp. 188-212. 
RES UMEN

El artículo describe la participación de uno de los grupos más conspicuos de la sociedad organizada en el país: la Asociación Mexicana del Derecho a la Información (Amedi), en el debate y las acciones políticas no partidarias alrededor de la democratización de los medios de comunicación masiva. A partir de una reflexión teórica sobre la participación de la sociedad civil en un diálogo con quienes toman las decisiones políticas para un mayor impulso democrático, se inscriben las propuestas y acciones de la Amedi en torno a las reformas constitucionales en materia de radiodifusión y telecomunicaciones de 2013. También se sostiene el posterior debate sobre las leyes reglamentarias propuestas por el gobierno de Enrique Peña Nieto, como aportaciones indispensables de la sociedad (no suficientemente valoradas por los actores políticos) al trabajo legislativo y a la calidad de la democracia en México.

PALABRAS CLAVE

Medios de comunicación, neoliberalismo, sociedad civil, reformas legislativas.
A B S T R A C T

This paper describes the participation of one of the most conspicuous groups of organized society in the country: the Mexican Society of the Right to Information (Asociación Mexicana del Derecho a la Información-Amedi), in the debate and non-partisan political actions about the democratization of mass media.

From a theoretical reflection about the participation of civil society in a dialog with political decision makers for a greater democratic impulse, the proposals and actions of the Mexican Society of the Right to Information are listed around the constitutional reforms in broadcasting and telecommunications from 2013.

It is also argued the subsequent debate on the regulatory laws proposed by Enrique Peña Nieto's Government, as indispensable contributions of society (not sufficiently valued by political actors) the legislative work and the quality of democracy in Mexico.

KEYWORDS

Media, Neoliberalism, Civil Society, Legislative Reforms.

\footnotetext{
* Profesora titular de tiempo completo en el Departamento de Sociología de la Universidad Autónoma Metropolitana - Iztapalapa, México.(vvme@xanum.uam.mx)
} 
1. Introducción / 2. Sociedad y Estado en el neoliberalismo / 3. Telecomunicaciones y radiodifusión en México / 4. La Amedi / 5. Reforma constitucional en telecomunicaciones y radiodifusión / 6. Participación de la Amedi en el debate sobre las leyes secundarias / 7. Reflexiones finales

\section{INTRODUCCIÓN}

Los dos principales grupos que controlan las industrias de la radiodifusión y las telecomunicaciones en México son tan fuertes que constituyen en los hechos contrapoderes frente al Estado. Se trata de grupos de presión que lo desafian para favorecer sus intereses económicos. Los actores políticos, en su mayoría, resultan incapaces de enfrentar a los dueños de las concesiones; gran parte de su imagen pública depende de ese oligopolio que controla la radio, televisión, telefonía fija y móvil, e internet en México. Por esa razón, es fundamental la participación activa de grupos sociales organizados en defensa de la libertad de expresión y el derecho a la información como pilares de la vida democrática.

En México, existen muchos grupos sociales interesados en este tema (sindicatos y gremios de comunicadores, escuelas de comunicación y múltiples ONG como la Asociación Mundial de Radios Comunitarias, Amarc, y otras). En este trabajo se eligió estudiar las principales propuestas y acciones de la Asociación Mexicana del Derecho a la Información (Amedi) en torno a las reformas constitucionales en materia de radiodifusión y telecomunicaciones aprobadas por los legisladores en junio de 2013. También estudiaremos el debate alrededor de las leyes reglamentarias propuestas por el gobierno de Enrique Peña Nieto en marzo del 2014. El objetivo fue plantear la perspectiva de esta organización como un caso específico en el análisis del papel de la sociedad organizada en los procesos legislativos, todo ello en una coyuntura particularmente importante en el país. Las reformas realizadas afectan a las industrias de telecomunicaciones y radiodifusión, es decir, los medios sin los cuales no es posible la comunicación política.

Además de la presente introducción y las reflexiones finales, el trabajo está estructurado en cinco apartados. En el primero se presenta la problemática de los medios de comunicación y el cambio del papel del Estado en la economía como un fenómeno común en América Latina, incluido México. Se reflexiona brevemente sobre la simultaneidad del fortalecimiento de la sociedad civil y la imposición del neoliberalismo económico en esos años. 
El segundo apartado analiza el impacto de la revolución tecnológica en el sector de las telecomunicaciones y la manera en que el proyecto neoliberal incidió en el fenómeno de fuerte concentración en esa industria. También se plantea la preocupación de grupos ciudadanos que se empezaron a organizar contra ese fenómeno por sus efectos negativos para la democracia, especialmente por la importancia de la televisión en los procesos electorales y el debate público.

El surgimiento de la Amedi, sus objetivos y propuestas para hacer efectivos el derecho a la información y la libertad de expresión se describen en el tercer apartado, con un breve análisis del contexto político que hizo posible el acuerdo de prácticamente todos los partidos políticos nacionales, el cual culminó con la aprobación, entre otras, de la reforma constitucional en materia de radiodifusión y telecomunicaciones, cuyo contenido puntual se estudia en el cuarto apartado.

El quinto y último apartado describe la participación de la Amedi en el debate sobre las leyes secundarias a partir de la propuesta que elaboró y logró que firmaran como iniciativa dieciocho senadores de la república en octubre de 2013, así como de la propuesta de ley enviada por el presidente Enrique Peña Nieto en abril del 2014. Ambas propuestas, la civil y la presidencial, eran divergentes en el propósito de democratizar la radiodifusión y las telecomunicaciones en México. La Amedi y otros sectores sociales lucharon para evitar que las leyes secundarias revirtieran los cambios trascendentales ya convertidos en normas inscritas en la Constitución.

Al final del artículo, hay una serie de reflexiones. Una de ellas señala una paradoja interesante en este tema: mientras la sociedad civil lucha contra la concentración en las industrias de las telecomunicaciones y la radiodifusión (porque repercute en la vida democrática del país que no haya una estructura de medios plural), con las decisiones políticas que han tomado en esas industrias, los gobiernos que han impulsado el modelo económico neoliberal que transformó al Estado desde hace más de treinta años en México demuestran su rechazo a las ideas en contra de los monopolios y acerca de la libre competencia, preceptos establecidos por ese mismo modelo.

\section{SOCIEDAD y ESTADO En EL NEOLIBERALISMO}

Hacia la mitad de la década de los setenta del siglo xx, en América Latina había interés por cambiar la situación de los medios masivos de comunicación pues casi todos estaban controlados por la iniciativa privada y eran operados de forma comercial. Ello implicaba poca o nula intervención estatal en el desarrollo de esta área tan importante para la economía y la cultura de cualquier país. En julio de 1976, bajo el auspicio de la UNESCO, representantes de veinte países de América Latina y el Caribe, incluido 
México, se reunieron en San José de Costa Rica para discutir políticas nacionales de comunicación. ${ }^{1}$

La reunión se planteó como objetivos la elaboración de políticas de medios que orientaran la inversión en infraestructura, determinaran niveles tecnológicos óptimos, coordinaran los sistemas de comunicación con metas de desarrollo económico, social y cultural, y racionalizaran la capacitación y el uso de recursos humanos. El fin era asegurar la producción en cada país y fortalecer la soberanía nacional, especialmente en el aspecto cultural. ${ }^{2}$

Pero pocos años después, quienes aspiraban al rescate nacional de los medios masivos de comunicación en América Latina se enfrentaron al avance de las ideas de libre mercado, privatización y eliminación del Estado benefactor. Se trató de la expresión regional de un proceso más amplio de la expansión del capitalismo global que parecía terminar con la controversia "entre los partidarios de la ideología de la libertad total del mercado y los defensores de la participación activa del Estado en la gestión económica". ${ }^{3}$ Eran las ideas del proyecto neoliberal.

$\mathrm{Al}$ igual que en el resto mundo, en México tal proyecto pretendía ser una respuesta integral a la crisis que, en los años setenta, acabó con la política económica que había acompañado al auge capitalista de la posguerra. Esta crisis implicó pérdida del poder adquisitivo del salario, desempleo e inflación en muchos países. ${ }^{4}$ El neoliberalismo ofreció entonces como salida "una óptima asignación de los recursos productivos, lo cual aseguraría la mejor y más justa distribución del ingreso entre las diferentes clases que concurren a la producción de bienes y servicios". ${ }^{5}$ Este ofrecimiento se fundamentaba teóricamente en la doctrina económica neoclásica que postula, por una parte, el restablecimiento de los mecanismos automáticos del sistema económico y, por otra, hace depender su regulación del libre juego de las fuerzas del mercado.

\footnotetext{
${ }^{1}$ Fox, Elizabeth, "La política de reforma de la comunicación en América Latina". Disponible en: http:// www.dialogosfelafacs.net/wp-content/uploads/2012/01/21-revista-dialogos-la-politica-de-reformade-la-comunicacion.pdf

${ }^{2}$ Idem.

${ }^{3}$ Gimeno Martín, Juan Carlos, "Antropólogos, pueblos indígenas y organizaciones no gubernamentales en América Latina en la era del neoliberalismo", en Óscar Calavia, Juan Carlos Gimeno y María Eugenia Rodríguez (eds.), Neoliberalismo, oNG y pueblos indígenas en América Latina, España, Sepha, 2007, p. 15.

${ }^{4}$ Los grandes desequilibrios y reestructuraciones económicas y políticas a nivel internacional afectaron también a México y una profunda crisis económica a partir de 1974 "desembocó en el estancamiento de la actividad económica, la inflación y la devaluación monetaria que tuvieron lugar sincronizadamente entre 1975 y 1977". Cordera, Rolando y Tello, Carlos, México: la disputa por la nación. Perspectivas y opciones del desarrollo, México, Siglo XXI, 1984, pp. 82 y 9.

${ }^{5}$ Puntualmente, las propuestas neoliberales en política económica eran: "[Reducir] al mínimo posible la participación del Estado en la economía así como su función reguladora; descansar en los instrumentos de la política monetaria (tasa de interés, control de circulante, etc.) más que en los de la política fiscal (gasto público, impuestos, etc.) para movilizar y asignar los recursos existentes y canalizar el excedente económico; privilegiar la estabilidad monetaria por encima de cualquier otro objetivo [...]; y, finalmente, liberar de trabas proteccionistas al intercambio de mercancías y capitales entre las naciones". Ibidem, pp. 82-83.
} 
De este modo, en México y muchos otros países el protagonismo estatal se fue desvaneciendo en muchas áreas de la economía en una nueva ola de modernización impulsada por el neoliberalismo que, expresado en términos tales como ajuste estructural, privatización, desregularización, libre comercio y desarrollo basado en el mercado, consiguieron que las economías nacionales y locales se abrieran al mercado mundial como nunca antes, y se desmantelaran y simplificaran las estructuras del Estado con una férrea disciplina financiera.

Por otra parte, el hueco que dejó la retirada parcial del Estado en la vida social se llenó con la participación y el nuevo protagonismo de la sociedad civil en los países de la región latinoamericana. Al finalizar el siglo, y debido a los procesos de democratización ocurridos en la mayoría de ellos, entraron al debate público nociones de buen gobierno, descentralización fiscal, participación en el desarrollo y lo que fue llamado empoderamiento de la sociedad civil. ${ }^{6}$

La entronización del neoliberalismo económico y la novedosa fuerza de la sociedad civil pueden analizarse como dos procesos paralelos que dieron como resultado una transformación del espacio político en América Latina, la cual, como en otras partes del mundo, se explica por el fortalecimiento de tendencias y movimientos de defensa y expresión de intereses, y por actores colectivos que se enfrentaron al protagonismo tradicional del Estado en la esfera pública. ${ }^{7}$ Desprovisto ya de su faz benefactora, el Estado tuvo que confrontarse con ciudadanos organizados con el fin de tener mayor participación en los asuntos públicos y, en muchos casos, para asumir la defensa del bienestar colectivo.

Hacia la última década del siglo pasado, tal cambio social era evidente en la región latinoamericana por la presencia de esos grupos ciudadanos que participaban no para dirigir al sistema político sino con intención de influirlo, "como una mediación entre la vivencia individual de los problemas sociales y la respuesta del aparato político a estos problemas". ${ }^{8}$ Por ello, se afirma que esos grupos de individuos forman parte del llamado "tercer sector" en el ámbito de la organización social, quienes "voluntariamente y sin ánimo de lucro - lo cual no está necesariamente reñido con su creciente profesionalización en determinados ámbitos - dirigen sus actividades hacia la prestación de diferentes servicios". ${ }^{9}$

\footnotetext{
${ }^{6}$ Gimeno Martín, Juan Carlos, Ibidem, p. 16.

${ }^{7}$ Peña, Javier, "La sociedad civil", en Aurelio Arteta, Elena García Guitián, Ramón Máiz (eds.), Teoría política: poder, moral, democracia, Madrid, Alianza, 2003, p. 196.

${ }^{8}$ Ibidem, p. 211.

${ }^{9} \mathrm{El}$ "tercer sector", del cual forma parte la sociedad civil, junto con el "segundo sector", el cual se compone de las empresas particulares que sí tienen intenciones de lucro, constituyen el terreno de la iniciativa privada, en oposición a la esfera de lo público (el "primer sector"). Esto implica, obviamente, que todas las organizaciones privadas sean en principio "no estatales" y "no gubernamentales". Bretón Solo de Zaldívar, Víctor, "Las organizaciones no gubernamentales y la privatización del desarrollo rural en América Latina”, en Óscar Calavia, Juan Carlos Gimeno y María Eugenia Rodríguez, op. cit., p. 55.
} 
La sociedad civil — concebida como una constelación de asociaciones diferenciadas del sistema político parcialmente orientadas a lo público con cierto acceso y repercusión en la esfera política - está íntimamente ligada a la ciudadanía, pues, según Habermas, "recoge los problemas de la sociedad y las demandas que se originan en la vida privada, los tematiza y articula, constituyendo así un vehículo de formación de opinión crítica y voluntad política, capaz de ejercer influencia y con ello tal vez un cierto control democrático del mercado y del sistema político". ${ }^{10}$

El impulso a la participación de la sociedad civil por parte de los representantes políticos tendría que darse por medio del diálogo, que "implica una conversación estructurada a partir de espacios de conflicto específicos y de la participación de actores informados e interesados [que] focaliza la atención de los participantes en un abanico limitado de asuntos, clarifica la posición de cada uno de ellos y, a través de escuchar y rebatir, se compromete a alcanzar conclusiones operativas". ${ }^{11}$ El diálogo favorece que la participación sea fuerte y capaz de impulsar la democracia, puesto que se da por medio de mecanismos que tratan de combinar información, deliberación y capacidad de intervención de los ciudadanos en los procesos de decisión. Si los políticos se lo proponen, pueden ofrecer el espacio donde los conflictos se hacen a la vez compresibles y resolubles para una red limitada de actores. Así, la participación se realiza y "puede desembocar en conclusiones concretas o, en otros términos, en capacidades reales de influir en las decisiones: el viejo tabú de la participación". ${ }^{12}$

\section{Telecomunicaciones y Radiodifusión en México}

El proyecto neoliberal tuvo un fuerte impulso en las industrias de la radiodifusión y de las telecomunicaciones durante los dos últimos sexenios presidenciales del viejo régimen político encabezado por el Partido Revolucionario Institucional (PRI). Entre los años 1988 y 2000, se realizaron transacciones económicas que dejaron en manos privadas a las empresas estatales de televisión abierta y telefonía. Además, se implementaron medidas legislativas que iban a marcar para la industria de las telecomunicaciones un derrotero donde la participación del Estado disminuyó considerablemente y dejó el papel protagónico a los inversionistas privados nacionales y extranjeros. ${ }^{13}$

\footnotetext{
${ }^{10}$ Peña, Javier, Ibidem, pp. 210-211.

${ }^{11}$ Brugué, Joaquim y Gallego, Raquel, “¿Una administración pública democrática?”, en Joan Font (coord.), Ciudadanos y decisiones públicas, Barcelona, Ariel, 2001, p. 46.

${ }^{12}$ Idem.

${ }^{13}$ Valdés Vega, María Eugenia, "Medios electrónicos y política en México: ¿del autoritarismo a la democracia?”, en Alicia Hernández de Gante, Adrián Gimate-Welsh y Manuel Alcántara (coords.), La reconfiguración neoliberal en América Latina, México, Miguel Ángel Porrúa - UAM Iztapalapa - BUAP - Universidad de Salamanca, 2010, pp. 245-251.
} 
Carlos Salinas (1988-1994) privatizó el Instituto Mexicano de Televisión (Imevisión), otorgándole en 1993 la concesión a Ricardo Salinas Pliego - quien a partir de ella creó TV Azteca- - Teléfonos de México, comprada por Carlos Slim durante su mandato. Su sucesor, Ernesto Zedillo (1994-2000), impulsó dos acciones legislativas trascendentales para las telecomunicaciones en México. Redujo la intervención del Estado en la industria de la televisión de paga o restringida, con la reforma al artículo 28 constitucional en enero de 1995, ya que se definió la comunicación vía satélite como actividad prioritaria y no estratégica exclusiva del Estado, como estaba clasificada anteriormente; ello permitió la inversión privada en este campo.

Por otro lado, se creó una nueva ley para "regular el uso, aprovechamiento y explotación del espectro radioeléctrico, de las redes de telecomunicaciones, y de la comunicación vía satélite", donde se entendía por telecomunicaciones "toda emisión, transmisión o recepción de signos, señales, escritos, imágenes, voz, sonidos o información de cualquier naturaleza que se efectúa a través de hilos, radioelectricidad, medios ópticos, físicos, u otros sistemas electromagnéticos", y en la cual se estableció la creación de la Comisión Federal de Telecomunicaciones (Cofetel). ${ }^{14}$

Este conjunto de decisiones políticas tuvo lugar en una etapa en la cual se dio un acelerado avance en las telecomunicaciones e inició la internacionalización de la televisión de paga; una verdadera revolución tecnológica que tenía su centro en el conocimiento. Según los economistas Sergio Ordóñez y Daniel Navarrete, a partir de los años ochenta del siglo pasado surgió una nueva fase de desarrollo del capitalismo, pues el conocimiento se constituyó en la principal fuerza productiva del crecimiento económico. ${ }^{15}$ Para estos autores, la revolución tecnológica de la informática y las comunicaciones hizo posible que el capitalismo diera un salto de calidad en la aplicación de la ciencia y el conocimiento en la producción social; logró articular inmediata e interactivamente al sector científico-educativo con la producción social a través, por un lado, del incremento en la capacidad de procesamiento de información y producción del conocimiento, el cual fue directamente accesible y aplicable a la producción. Ello se debió, respectivamente, al desarrollo del microprocesador y el software; por otro lado, mediante "el incremento dramático en la velocidad y la escala de acceso y difusión del conocimiento y la información, resultado de la confluencia de la informática y las telecomunicaciones, y del desarrollo de éstas". ${ }^{16}$

Como consecuencia de las decisiones políticas que pusieron a los servicios de telecomunicaciones en manos de unos cuantos individuos, ellos fueron

\footnotetext{
${ }^{14}$ Ley Federal de Telecomunicaciones, artículos 1 y 3, 7 de junio de 1995.

${ }^{15}$ Ordóñez, Sergio y Navarrete, Daniel, "Industria de servicios de telecomunicaciones y reforma regulatoria en México", Revista Problemas del Desarrollo, vol. 47, núm. 184, 2016, p. 38.

${ }^{16}$ Ibidem, pp. 38-39.
} 
los principales beneficiados de la revolución tecnológica. Eso es evidente en las características centrales de la modalidad de desarrollo de esa industria en México: 1) la telefonía determina a la industria, ya que representa $89 \%$ de la producción bruta total; 2) existe un sobreprecio del servicio telefónico fijo (en 2011 era de 69.77 dólares en México y de 43.69 en promedio en 64 países), así como de los servicios de internet; 3) se han producido ganancias extraordinarias como resultado del sobreprecio; ${ }^{17}$ 4) hay baja tasa de penetración de la telefonía fija y móvil, así como de internet y banda ancha, con baja cobertura de estos últimos servicios; 5) se dan altos niveles de centralización de capital, producción y empleo, lo cual se traduce en una alta concentración de los mercados de la industria en su conjunto; 6) la centralización de la producción se corresponde con una "concentración de su despliegue espacial-territorial en la región central del país, específicamente el Distrito Federal y zona conurbada". ${ }^{18}$

Así, la vía de desarrollo neoliberal seguida en el país provocó que la industria de los servicios de telecomunicaciones tuviera un despliegue que la condujo a caracterizarse por redes controladas monopólicamente, gestión rentista, y diferenciación regional. Esto resultó de un desarrollo espacial desigual de los servicios proporcionados por la industria en escala nacional ("de arriba abajo"), en lugar de hacerlo "conforme a una diferenciación regional específica de la industria de acuerdo con los servicios combinados requeridos en cada región" ("de abajo arriba"). ${ }^{19}$

En lo que respecta a la industria de la radiodifusión, concretamente la televisión abierta - que para fines de comunicación política sigue siendo muy importante en México - , los niveles de concentración son asimismo demasiado altos. La actualmente desaparecida Comisión Federal de Telecomunicaciones (Cofetel) presentó un informe en 2012 donde señalaba que pertenecían a Televisa 224 de las 461 estaciones concesionadas de televisión abierta en el país; otras 34 estaciones afiliadas transmitían también su programación; mientras que TV Azteca contaba con 180 estaciones. Aunque entre las dos empresas acaparaban 95\% de las concesiones, más de la mitad eran de Televisa; con ello, controlaba el contenido trasmitido a todo el país (cuadro 1$) \cdot{ }^{20}$

\footnotetext{
${ }^{17}$ Esta ganancia extra "ha financiado una vertiginosa expansión internacional [del empresario Carlos Slim] hacia Latinoamérica que la ha llevado a obtener una cuota de mercado de alrededor de $50 \%$ en telefonía móvil y $33 \%$ en telefonía fija, y a disputarse el control del mercado latinoamericano con la empresa española Telefónica". Ibidem, p. 44.

${ }^{18}$ Ibidem, p. 45.

${ }^{19}$ Según Ordóñez y Navarrete, "es necesario trascender la trayectoria analítica y regulatoria abierta por la Reforma y ubicarse en la perspectiva de la vía de desarrollo del tránsito al capitalismo del conocimiento para estar en condiciones de promover un auténtico cambio en la modalidad de desarrollo de la industria, que la oriente hacia la innovación y la diferenciación productiva y espacial 'de abajo arriba' de los servicios proporcionados". Ibidem, pp. 43 y 37.

${ }^{20}$ Comisión Federal de Telecomunicaciones. Informe de resultados (2006-2012). Disponible en: http://www. cft.gob.mx:8080/portal/wp-content/uploads/2012/11/INFORME-CFT-2006-2012.pdf
} 
Cuadro 1: Distribución de las concesiones de televisión abierta en México

\begin{tabular}{|c|c|c|}
\hline Empresas televisoras & Estaciones concesionadas & Porcentaje \\
\hline Televisa & 258 & $56 \%$ \\
\hline TV Azteca & 180 & $39 \%$ \\
\hline Otras & 23 & $5 \%$ \\
\hline Total & 461 & $100 \%$ \\
\hline
\end{tabular}

Fuente: Elaboración propia con datos de Cofetel.

Carlos Slim y Emilio Azcárraga, los dos usufructuarios de esta alta concentración en telecomunicaciones y radiodifusión, respectivamente, se enfrascaron en una lucha por acceder a los negocios derivados de la convergencia tecnológica. ${ }^{21}$ Las empresas de estos dos magnates se disputaban los nuevos y florecientes mercados de la televisión de paga y de telefonía móvil. ${ }^{22}$

La estructura concentrada de la industria y la escasa pluralidad de contenidos derivada de ella (especialmente de la televisión, dada su creciente importancia en los procesos electorales y políticos) originaron la preocupación de muchos ciudadanos por su repercusión en la vida democrática del país. De esta suerte, desde fines de los años setenta se organizaron algunos grupos para demandar la democratización de los medios.

Durante las dos décadas siguientes, en las cuales se impuso el proyecto neoliberal en México, estos grupos coincidieron con numerosas organizaciones de carácter civil que tenían diversos objetivos y actividades. En muchos casos, surgieron a partir de movimientos sociales que involucraron a amplios sectores con intereses y demandas específicos: obreros industriales, asalariados del campo y la ciudad, campesinos, indígenas, colonos demandantes de vivienda y servicios, trabajadores universitarios, profesores de educación básica y media superior, intelectuales y artistas, entre otros.

También surgieron otras organizaciones de grupos sociales más pequeños y especializados en temas de interés general que paulatinamente ganaron espacios en el debate público del país, particularmente en los años noventa.

\footnotetext{
${ }^{21}$ La revolución tecnológica en las telecomunicaciones llevó a la convergencia de redes de comunicación, cómputo y radio y televisión, "gracias a las redes digitales, las nuevas tecnologías de transmisión y almacenamiento de datos, en particular la fibra óptica, las comunicaciones por satélite y el software avanzado". Castells, Manuel, Comunicación y poder, México, Siglo XXI, 2015, p. 92.

${ }^{22}$ La empresa Dish, con participación y gestión financiera de Telmex, tenía antes de la reforma 16.6\% del mercado de televisión de paga, así como las empresas de telefonía móvil Iusacel y Unefon eran propiedad del Grupo Salinas (TV Azteca) y de Televisa, respectivamente. Además, Televisa tiene como empresas filiales a Cablevisión, Corporación Novavisión-Sky, Cablemás, Telecomunicaciones y Televisión Internacional. Garduño, Roberto y Méndez, Enrique, "Avalan diputados leyes secundarias", La fornada, 9 de julio de 2014, p. 2. Méndez, Alfredo, "Revés a filiales de Televisa sobre exclusividad de trasmisiones", $L a$ Fornada, 8 de julio de 2014, p. 3.
} 
Ese fue el caso de los grupos ciudadanos interesados en la democratización de los medios de comunicación que, por ello, entraron al debate de las políticas para su regulación.

$\mathrm{Al}$ margen de los partidos y representantes gubernamentales, estos grupos, compuestos principalmente por intelectuales, periodistas y académicos, se organizaron y trataron de influir en la elaboración de las políticas que debería implementar el gobierno en los medios, especialmente la radio y la televisión. Una de ellas fue la Asociación Mexicana del Derecho a la Información (Amedi).

\section{LA AMEDI}

Sin fines lucrativos, la Amedi se fundó en 2001 con tres objetivos principales: 1) "Promover el irrestricto respeto, por parte de las instituciones gubernamentales y los medios de comunicación, de los derechos relacionados con la obligación legal y ética de garantizar a los mexicanos información veraz y objetiva sobre los asuntos de interés público". 2) "Impulsar la discusión pública sobre el cumplimiento de las garantías relacionadas con las libertades de expresión e información y el derecho a la información". 3) "Evaluar y documentar, por sí o a través de los organismos [que tengan como fin generar una conciencia clara y precisa sobre los derechos y responsabilidades de los diversos actores del proceso comunicativo], las violaciones de los preceptos legales establecidos en el orden jurídico mexicano para garantizar el cumplimiento de las garantías relacionadas con el derecho a la información". ${ }^{23}$

Para la Amedi, la garantía del derecho a la información del artículo 6 constitucional (solitaria conquista obtenida en la reforma política de 1977) es "la piedra angular del pleno ejercicio de la libertad de expresión”. ${ }^{24}$ Sin embargo, como no se reglamentó por décadas, para esta organización es obvio que en México el poder de la información está condicionado por el mercado y por la discrecionalidad en su ejercicio, debido a lo cual no está sujeto a ningún tipo de responsabilidades. Esa es la razón por la cual planteó como imperativo actualizar el marco jurídico para armonizar la libertad de expresión y el derecho a la información "como derechos sociales básicos que demandan la participación ciudadana y la necesidad colectiva de tener acceso a la información". ${ }^{25}$

De acuerdo con la Amedi, al terminar la primera década del siglo XxI, uno de los grandes pendientes de la llamada reforma de los medios era, "en primer lugar, la reafirmación del papel rector del Estado en materia de comunicación y en particular, la reglamentación del derecho a la información”.

\footnotetext{
${ }^{23}$ Asociación Mexicana de Derecho a la Información, "Estatutos". [Consulta: 25 de junio, 2014]. Disponible en: http://www.amedi.org.mx/estatutos/

${ }^{24}$ Asociación Mexicana de Derecho a la Información, "Licitación de frecuencias de radio AM y FM debe incremental la pluralidad". [Consulta: 25 de junio, 2014]. Disponible en: http://www.amedi.org.mx/ index.php?option $=$ com_content\&view $=$ article\&id $=77 \&$ Itemid $=75$

${ }^{25} \mathrm{Idem}$.
} 
La Amedi hacía notar que si bien desde 1977 la sociedad mexicana fue convocada en numerosas ocasiones para consultarla sobre este tema - lo cual produjo infinidad de propuestas y demandas que ratificaban la necesidad de la legislación-, siempre se manifestaron los intereses contrarios a atender esas demandas en referencia implícita a los dueños de las concesiones en radiodifusión y telecomunicaciones.

Ante ello, el argumento de la Amedi es que la generación de políticas públicas y su necesaria reflexión deben dejar de ser asunto de unos cuantos, ya que de ellas dependerá la definición de formas de interrelación de los seres humanos en la sociedad. Dado que el derecho a la información tiene carácter social, donde el interés público está presente, "nadie mejor que la propia sociedad para promover su ejercicio, vigilar su aplicación y estimular su debida actualización jurídica", ${ }^{26}$

La Amedi ha sido muy clara en cuanto sus tareas y propuestas. Parte de una noción del concepto de libertad de información como "la posibilidad efectiva y real de toda persona de investigar, recibir, producir y difundir información de toda índole a través de cualquier procedimiento o medio de su elección”. Para ello, es indispensable la plena garantía del derecho a la información, "entendido como la facultad de toda persona a solicitar y recibir, sobre cualquier asunto de interés público, información oportuna, veraz, plural y suficiente". ${ }^{27}$

Los integrantes de esta asociación consideran que la garantía de este derecho corresponde al Estado con el sólido razonamiento de que, al incorporarlo a la Constitución en 1977, el poder legislativo estaba obligado a reglamentarlo desde entonces. Para ellos, el cumplimiento de ese derecho era fundamental para el ejercicio de la libre expresión por parte de los profesionales de los medios, de la cual sería beneficiaria principalmente la sociedad. ${ }^{28}$

Además, la Amedi planteó que sería necesario precisar y regular un conjunto de derechos y obligaciones con el fin de:

Garantizar el respeto a los derechos correlativos al genérico derecho a la información: la vida privada, la dignidad, la honra y el buen nombre de cualquier ciudadano, lo que se denomina derecho a la privacidad, al igual que el derecho de réplica [así como] el respeto a la integridad del trabajo profesional, del secreto de sus fuentes informativas, y la libertad de conciencia del comunicador. ${ }^{29}$

\footnotetext{
${ }^{26}$ Idem.

${ }^{27} \mathrm{Idem}$.

${ }^{28}$ La Amedi está conformada básicamente por periodistas, comunicadores y académicos, pero en su consejo consultivo se encuentran además destacados políticos de los principales partidos, así como intelectuales y artistas reconocidos nacional e internacionalmente. Los presidentes de la asociación duran en su cargo dos años y los últimos han sido: Javier Corral (2007-2009), Raúl Trejo Delarbre (2009-2011), Aleida Calleja Gutiérrez (2011-2013) y Agustín Ramírez Ramírez (2013-2015).

${ }^{29}$ Idem.
} 
Las propuestas concretas de la Amedi se han enfocado durante largo tiempo en la lucha por que el poder político se imponga a los intereses de los poderosos empresarios de los medios en el país. Si se observa, la mayoría de esas propuestas involucra intereses sociales; podrían ser suscritas por cualquier ciudadano en el mundo, al igual que las referidas al trabajo que desarrollan periodistas y comunicadores en México, las cuales serían firmadas por periodistas a nivel internacional (véase cuadro 2).

\section{Cuadro 2: Propuestas de la Asociación Nacional de Derecho a la Información}

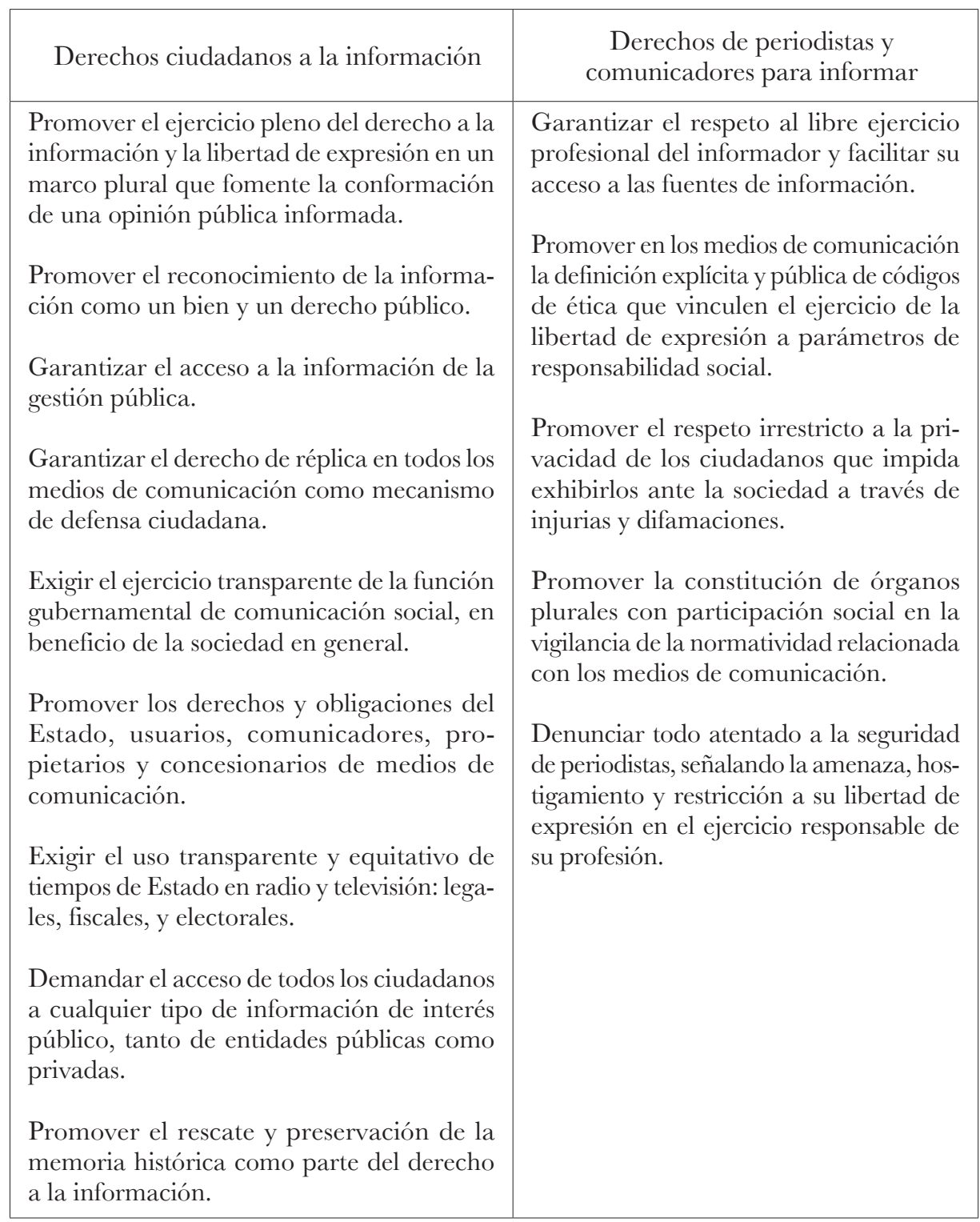

Fuente: Asociación Mexicana de Derecho a la Información. Disponible en www.amedi.org.mx 
En su lucha por garantizar el derecho a la información, ligado a su defensa a la libertad de expresión, la Amedi tuvo vínculos con uno de los movimientos sociales más importantes y exitosos que ha tenido lugar en México: \#YoSoy $132 .{ }^{30}$

Con esos antecedentes, el tema de una reforma legislativa se impuso desde las primeras acciones del presidente Enrique Peña Nieto, del Partido Revolucionario Institucional (PRI), a la cabeza del gobierno federal tras las elecciones de julio de 2012. Dado el contexto de cambios sociales y políticos ocurridos en los doce años que gobernó el Partido Acción Nacional (PAN), el también jefe del poder ejecutivo se vio obligado a tejer acuerdos de gobernabilidad. Ese fue el origen del Pacto por México, un consenso entre las principales fuerzas políticas firmado el 2 de diciembre de 2012 que buscaba transformar al país a partir de 95 acciones que comenzarían a implementarse en el primer año del nuevo gobierno. ${ }^{31}$

El tema fue abordado por el presidente de la república desde su primer discurso en diciembre de 2012, donde anunció la licitación de dos nuevas cadenas de televisión abierta y su intención de enviar al poder legislativo un conjunto de iniciativas de reforma con el objetivo de generar una mayor competencia económica, "particularmente en el sector de las telecomunicaciones". ${ }^{32}$

No obstante que por fin parecía que se solucionarían sus demandas, las organizaciones dedicadas a estos temas mostraron cautela y escepticismo ante las promesas del Pacto por México. La entonces presidenta de Amedi señaló que, si bien ese acuerdo abarcaba la mayor parte de lo que durante décadas habían sido exigencias ciudadanas, tenía dos omisiones importantes. Por un lado, estaban excluidos los medios públicos y los comunitarios "que conforman lo poco que tenemos de pluralismo". Por otro lado, no se sabía acerca de los avances en la propuesta para la protección a periodistas que ya existía y debía funcionar con eficacia, porque este sector había sido muy lastimado en los últimos años. ${ }^{33}$

\footnotetext{
${ }^{30}$ El movimiento de estudiantes universitarios conocido como \#YoSoy132 surgió en la campaña electoral de 2012. Aunque tuvo su escenario principal en la Ciudad de México, también se extendió a muchas otras ciudades del país. Sus demandas más difundidas fueron la equidad en el manejo informativo de la televisión abierta y la limitación de la influencia de Televisa en la elección presidencial que había sido denunciada varios años antes. Otras demandas estaban orientadas a evitar el fenómeno de la concentración de los medios masivos de comunicación. Fue en ese punto donde los estudiantes coincidieron con la Amedi. Véase Valdés Vega, María Eugenia y Maldonado Montes, Josefina, "El reclamo democrático del movimiento \#YoSoy 132", en Héctor Tejera, Pablo Castro y Emanuel Rodríguez (coords.), Continuidades, rupturas y regresiones. Contradicciones y paradojas de la democracia mexicana, México, UAMI - Juan Pablos Editor, 2014.

${ }^{31}$ Guerrero, Claudia y Hernández, Érika, "Ya hay Pacto", Reforma, 3 de diciembre, 2014.

${ }^{32}$ Baranda, Antonio y Arteta, Itxaro, "Promete EPN renovación", Reforma, 2 de diciembre, 2014.

${ }^{33}$ Calleja, Aleida, "Nuevo, pero sin mucha definición", en Ernesto Núñez, Jésica Zermeño y Martha Martínez, "El pacto y sus asegunes", Reforma, suplemento Enfoque, 9 de diciembre de 2012.
} 
Además, cuestionaba que no tuviera una visión integral y puso como ejemplo la propuesta de nuevas cadenas de televisión abierta. No bastaba su licitación si no se determinaba la entrada de nuevos jugadores para fortalecer el pluralismo con la llamada multiprogramación derivada de la televisión digital terrestre, ya que "de entrada generará una mayor concentración si esas nuevas señales quedan en los operadores actuales de la radiodifusión”. Para eso, se requería un nuevo marco normativo integral, que las fuerzas políticas mantuvieran su capacidad para lograr acuerdos y que tuvieran el valor para enfrentar las resistencias de los poderes fácticos. Su conclusión era que había sobradas razones para sospechar que el pacto sólo serviría "para transar acuerdos sin llegar a los cambios de fondo, como ha sucedido con otros gobiernos". La tarea de la sociedad debía centrarse en "exigir su cumplimiento y un diálogo abierto para conocer a detalle las propuestas con mecanismos de inclusión para su construcción, pues en el qué y el cómo están las claves para que se hagan realidad cuanto antes". ${ }^{34}$

\section{REFORMA CONSTITUCIONAL EN TELECOMUNICACIONES Y RADIODIFUSIÓN}

Tras ser aprobadas por las dos cámaras del Congreso de la Unión y por la mayoría de las legislaturas de los estados, se publicó la reforma constitucional en radiodifusión y telecomunicaciones el 11 de junio de 2013. Tales reformas incluían aspectos muy importantes que habían demandado las organizaciones sociales en lucha por la democratización de los medios en México.

\subsection{Artículo 6}

Además de que el Estado debe garantizar la libre manifestación de las ideas, excepto "en el caso de que ataque a la moral, la vida privada o los derechos de terceros, provoque algún delito, o perturbe el orden público", la reforma precisó que la garantía del derecho a la información también debía ser una obligación estatal y que todas las personas podrían tener "libre acceso a información plural y oportuna, así como a buscar, recibir y difundir información e ideas de toda índole por cualquier medio de expresión”. Se incluyó el derecho de réplica y el Estado se comprometió a establecer condiciones de competencia efectiva en la prestación de los servicios de radiodifusión y telecomunicaciones, incluido el de banda ancha e internet, para garantizar el derecho de acceso a las tecnologías de la información y comunicación. ${ }^{35}$

\footnotetext{
${ }^{34}$ Idem.

${ }^{35}$ Decreto por el que se reforman y adicionan diversas disposiciones de los artículos 6, 7, 27, 28, 73, 78, 94 y 105 de la Constitución Política de los Estados Unidos Mexicanos, en materia de telecomunicaciones. Diario Oficial de la Federación, 11 de junio, 2013.
} 
Constitucionalmente, a partir de esta reforma es un compromiso del Estado el diseño de una política de inclusión digital universal con metas anuales y sexenales para garantizar que la población se integre a la sociedad de la información y el conocimiento. Asimismo, que las telecomunicaciones sean un servicio que se preste "en condiciones de competencia, calidad, pluralidad, cobertura universal, interconexión, convergencia, continuidad, acceso libre y sin injerencias arbitrarias". Además de competencia y calidad, la radiodifusión, el otro servicio público de interés general que es materia de esta reforma, debe brindar "los beneficios de la cultura a toda la población, preservando la pluralidad y la veracidad de la información, así como el fomento de los valores de la identidad nacional", para que contribuya a los fines educativos establecidos en el artículo 3 de la Constitución. ${ }^{36}$

Con el fin de garantizar el ejercicio del derecho a la información, se prohíbe la transmisión de publicidad o propaganda presentada como información periodística o noticiosa, se establecen los derechos de los usuarios de telecomunicaciones y se crea un organismo público descentralizado y autónomo: el Instituto Federal de Telecomunicaciones (IFT), con el fin de:

Proveer el servicio de radiodifusión sin fines de lucro, a efecto de asegurar el acceso al mayor número de personas en cada una de las entidades de la Federación, a contenidos que promuevan la integración nacional, la formación educativa, cultural y cívica, la igualdad entre mujeres y hombres, la difusión de información imparcial, objetiva, oportuna y veraz del acontecer nacional e internacional, y dar espacio a las obras de producción independiente, así como a la expresión de la diversidad y pluralidad de ideas y opiniones que fortalezcan la vida democrática de la sociedad. ${ }^{37}$

La reforma constitucional estableció que el presidente del IFT debe ser designado a propuesta del presidente de la república con el voto de dos terceras partes de los miembros presentes de la Cámara de Senadores o, en sus recesos, de la Comisión Permanente. "Durará en su encargo cinco años, podrá ser designado para un nuevo periodo por una sola vez, y sólo podrá ser removido por el Senado mediante la misma mayoría." Presentará un informe anual de actividades a los poderes Ejecutivo y Legislativo de la Unión. ${ }^{38}$

\footnotetext{
${ }^{36}$ Idem.

${ }^{37}$ Idem.

${ }^{38}$ En este artículo se prevé la creación de un Consejo Ciudadano para asegurar la independencia y una política editorial imparcial y objetiva en el IFT, integrado por nueve consejeros honorarios elegidos mediante una amplia consulta pública por el voto de dos terceras partes de los miembros presentes de la Cámara de Senadores o, en sus recesos, de la Comisión Permanente, quienes desempeñarán su encargo en forma escalonada. Idem.
} 


\subsection{Artículo 7}

Se actualizó la garantía de inviolabilidad de la libre difusión de opiniones, información e ideas, a través de cualquier medio. Según la reforma, este derecho no puede restringirse "por vías o medios indirectos, tales como el abuso de controles oficiales o particulares, de papel para periódicos, de frecuencias radioeléctricas o de enseres y aparatos usados en la difusión de información o por cualesquiera otros medios y tecnologías de la información y comunicación encaminados a impedir la transmisión y circulación de ideas y opiniones". Está garantizado que de ninguna manera puede establecerse la previa censura, ni coartarse la libertad de difusión, cuyos límites son solamente los previstos en el primer párrafo del artículo 6 constitucional y que en ningún caso "podrán secuestrarse los bienes utilizados para la difusión de información, opiniones e ideas, como instrumento del delito". ${ }^{39}$

Para hacer efectivos los derechos de libertad de expresión y acceso a la información, fueron reformados los artículos 27 y 28 de la Carta Magna que igualmente son relevantes debido a que se refieren a los recursos necesarios para lograr esos objetivos.

\subsection{Artículo 27}

Cuando se aprobaron los cambios en materia de telecomunicaciones en mayo de 2013, se reformó sólo un párrafo de este artículo, pero volvió a reformarse en diciembre del mismo año con motivo de la reforma energética. Tanto a mediados como a fines de 2013 se mantuvo - como se hizo desde el constituyente de 1917- que la nación es la propietaria original de las tierras y aguas comprendidas dentro de los límites de su territorio, lo que le confiere "el derecho de transmitir el dominio de ellas a los particulares, constituyendo la propiedad privada”. Igualmente, continuó la norma de que las "expropiaciones sólo podrán hacerse por causa de utilidad pública y mediante indemnización". ${ }^{40}$

Pero en mayo e igualmente en diciembre de 2013 se evitó tocar los dos párrafos que establecen el dominio o la propiedad nacional en el subsuelo, espacio aéreo y aguas. En el párrafo que sí fue reformado, el artículo 27 señala que "el dominio de la Nación es inalienable e imprescriptible y la explotación, el uso o el aprovechamiento de los recursos de que se trata, por los particulares o por sociedades constituidas conforme a las leyes mexicanas, no podrá realizarse sino mediante concesiones". Tales concesiones deberá otorgarlas

\footnotetext{
${ }^{39}$ Constitución Politica de los Estado Unidos Mexicanos, artículo 7.

${ }^{40}$ Constitución Política de los Estados Unidos Mexicanos, artículo 27.
} 
el presidente de la república, "salvo en radiodifusión y telecomunicaciones, que serán otorgadas por el Instituto Federal de Telecomunicaciones". ${ }^{41}$

\subsection{Artículo 28}

La reforma creó una Comisión Federal de Competencia Económica (Cofeco) como un órgano autónomo del Estado, con personalidad jurídica y patrimonio propio, para "garantizar la libre competencia y concurrencia, así como prevenir, investigar y combatir los monopolios, las prácticas monopólicas, las concentraciones y demás restricciones al funcionamiento eficiente de los mercados". Esta institución era necesaria porque la radiodifusión y telecomunicaciones están altamente concentradas en México.

El Instituto Federal de Telecomunicaciones (IFT), la nueva institución establecida por la reforma, tiene autonomía, personalidad jurídica y patrimonio propio. Está destinado al desarrollo eficiente de la radiodifusión y las telecomunicaciones. Entre las amplias funciones de este organismo están la regulación, promoción y supervisión del uso, aprovechamiento y explotación del espectro radioeléctrico, las redes y la prestación de los servicios de radiodifusión y telecomunicaciones, así como del acceso a infraestructura activa, pasiva y otros insumos esenciales. Sólo ella es "la autoridad en materia de competencia económica de los sectores de radiodifusión y telecomunicaciones", de suerte que está facultada para ejercer en esos sectores el papel que la Constitución y las leyes le otorgan a la Cofeco. ${ }^{42}$

Además, el IFT también tiene las siguientes facultades que marcan positivamente la reforma constitucional pues reducen considerablemente la posibilidad de uso discrecional del poder político sobre este bien público.

- Regular de forma asimétrica a los participantes en estos mercados con el objeto de eliminar eficazmente las barreras a la competencia y la libre concurrencia.

- Imponer "límites a la concentración nacional y regional de frecuencias, al concesionamiento y a la propiedad cruzada que controle varios medios de comunicación que sean concesionarios de radiodifusión

\footnotetext{
${ }^{41}$ En este párrafo del artículo 27 se puede observar una diferencia relevante entre la reforma de las telecomunicaciones decretada en junio de 2013 y la energética realizada en diciembre del mismo año. Cuando volvió a reformarse en diciembre, se agregó un párrafo para reafirmar que el petróleo y los hidrocarburos sólidos, líquidos y gaseosos son propiedad inalienable e imprescriptible de la nación, y para señalar que en esos casos no se otorgarán concesiones. La diferencia es notable, ya que en esta última reforma, por un lado, se quita la exclusividad del Estado sobre la generación, conducción y transformación de energía eléctrica para el servicio público; por otro, se abre la puerta para que particulares participen en las actividades de exploración y extracción de petróleo mediante asignaciones a empresas productivas del Estado o a través de contratos. Idem.

${ }^{42}$ Constitución Política de los Estados Unidos Mexicanos, artículo 28.
} 
y telecomunicaciones que sirvan a un mismo mercado o zona de cobertura geográfica", y ordenar "la desincorporación de activos, derechos o partes necesarias para asegurar el cumplimiento de estos límites".

- Otorgar la revocación de concesiones y autorizar cesiones o cambios de control accionario, titularidad u operación de sociedades relacionadas con concesiones en materia de radiodifusión y telecomunicaciones.

- Fijar el monto de las contraprestaciones por el otorgamiento de las concesiones, así como por la autorización de servicios vinculados a éstas, previa opinión de la autoridad hacendaria. ${ }^{43}$

A partir de esta reforma, el otorgamiento de las concesiones del espectro radioeléctrico se realizará mediante licitación pública. Las concesiones para uso público y social serán sin fines de lucro y se otorgarán bajo el mecanismo de asignación directa. De acuerdo con la reforma, la ley deberá establecer un esquema efectivo de sanciones para revocar el título de concesión cuando, entre otras causas, se incumplan resoluciones firmes sobre prácticas monopólicas. ${ }^{44}$

Una excelente noticia fue que la Cofeco y el IFT serían "independientes en sus decisiones y funcionamiento, profesionales en su desempeño e imparciales en sus actuaciones". ${ }^{45}$

\section{Participación de la Amedi en el debate SOBRE LAS LEYES SECUNDARIAS}

Las reformas constitucionales en materia de radiodifusión y telecomunicaciones fueron consideradas un triunfo por quienes habían luchado largamente en la contención del poderío de los empresarios dueños de las concesiones. Este logro no fue sólo de los pequeños grupos especializados, sino que fueron involucrados amplios sectores sociales que asimismo tenían motivos para sentirse satisfechos. Pero la iniciativa de leyes reglamentarias presentada el 24 de marzo de 2014 por el gobierno del presidente Enrique Peña Nieto echó por tierra la sensación de triunfo.

La Amedi había entregado una propuesta regulatoria desde octubre de 2013 a algunos legisladores de diversos partidos y había conseguido que dieciocho senadores la suscribieran. De ese modo, el proyecto ciudadano se

\footnotetext{
${ }^{43}$ Idem.

${ }^{44}$ Idem.

${ }^{45}$ La reforma previó que los órganos de gobierno tanto de la Cofeco como del IFT se integrarían por siete comisionados, incluyendo el comisionado presidente, designados en forma escalonada a propuesta del presidente de la república con la ratificación del Senado. El presidente de cada uno de los órganos sería nombrado por la Cámara de Senadores de entre los comisionados, por el voto de las dos terceras partes de los miembros presentes, por un periodo de cuatro años, renovable por una sola ocasión.
} 
convirtió formalmente en iniciativa de ley. Por esta razón, en un foro organizado por el Senado de la República, los primeros días de abril de 2014, la Amedi reclamaba que haber suscrito una iniciativa originada en la sociedad civil era un acto altamente significativo que debían honrar los legisladores impulsando una discusión rigurosa de la propuesta del ejecutivo federal y contrastar su contenido con la iniciativa ciudadana. No hacerlo "convertiría el proceso en una farsa". En voz de su presidente, Agustín Ramírez Ramírez, la asociación expresó sus argumentos en contra de la iniciativa presidencial, los cuales sintetizan sus aspectos negativos.

Para esa organización, la iniciativa presidencial pervertía la finalidad de la reforma constitucional, pues estaba muy alejada del propósito que le dio origen, es decir, satisfacer los derechos fundamentales de libertad de expresión, derecho a la información y derecho de acceso a las tecnologías de la información y la comunicación, así como las condiciones para una efectiva competencia en los servicios de radiodifusión y telecomunicaciones. Por otro lado, pretendía un regulador débil, supeditado a los intereses del ejecutivo federal, pues permitiría a la Secretaría de Gobernación conservar la vigilancia de los servicios de radio y televisión, incluidos los tiempos de Estado y la publicidad; que la Secretaría de Comunicaciones y Transportes opinara de manera indebida sobre el programa de trabajo y los informes de labores del IFT; y que la Comisión Federal de Mejora Regulatoria de la Secretaría de Economía opinara previamente sobre los proyectos regulatorios del Instituto. ${ }^{46}$

La iniciativa, de acuerdo con la Amedi, desfiguraba el principio de neutralidad de la red, condición básica para garantizar el acceso universal a las tecnologías de la información y la comunicación. Además, permitía la interferencia de comunicaciones sin un estricto control judicial, violando principios básicos de derechos humanos y dejaba al arbitrio de los concesionarios los tiempos de Estado, ya que la Secretaría de Gobernación debía escuchar previamente a los concesionarios y fijar los horarios de transmisión de acuerdo con ellos.

Por otro lado, ignoraba los derechos de las audiencias, contraviniendo de esa manera la disposición constitucional que ordena establecerlos en la ley, así como mecanismos para su protección. No bastaba enlistar un reducido catálogo de principios generales y mucho menos señalar que la promoción y defensa de dichas prerrogativas ciudadanas estarían en los códigos de ética de los concesionarios.

Asimismo, ignoraba la importancia de los medios públicos y de uso social pues contenía una "omisión grosera" en lo que correspondía a los medios

\footnotetext{
${ }^{46}$ Asociación Mexicana de Derecho a la Información. [Consulta: 28 de junio, 2014]. Disponible en: http://www.amedi.org.mx/prensa/comunicados/869-cronica-de-un-despojo-los-derechos-fundamentales-en-la-iniciativa-de-ley-en-telecomunicaciones-y-radiodifusion
} 
públicos. Desestimó los principios del artículo décimo transitorio para que contaran con independencia editorial; autonomía de gestión financiera; garantías de participación ciudadana; reglas claras para la transparencia y rendición de cuentas; defensa de sus contenidos; opciones de financiamiento; pleno acceso a tecnologías, y reglas para la expresión de diversidades ideológicas, étnicas y culturales. Adicionalmente, excluía a los de las instituciones de educación superior entre los medios de uso público. La Amedi afirmaba que, contrario a la obligación legal de introducir un régimen favorable para el desarrollo de los medios públicos, comunitarios e indígenas, se les asfixiaba con requisitos discrecionales, además de prohibiciones para contar con fuentes de financiamiento.

La iniciativa no introducía un mecanismo expedito para el otorgamiento de concesiones para los medios de uso social y les imponía un régimen de acceso a las frecuencias inequitativo y arbitrario al ponerles las mismas condiciones que a los medios de uso público. En cambio, señalaba la Amedi, establecía un régimen muy favorable para los medios comerciales, a los cuales se les otorgarían incentivos en materia de publicidad, contenidos y multiprogramación, entre otras cosas. Se introducía una regulación engorrosa de la concesión única, que promovía la prestación de servicios adicionales y convergentes sin delimitar con precisión los requisitos para su autorización, además de otorgarla por treinta años de vigencia.

El presidente Enrique Peña Nieto proponía con su iniciativa diluir la obligación de establecer límites a la concentración de frecuencias y a la propiedad cruzada, contra lo dispuesto por el artículo 28 constitucional. Además, omitía regular la atribución de la Cofeco para ordenar la desinversión con el propósito de asegurar el cumplimiento de los límites que debían establecerse con anterioridad. La Amedi aseguraba entonces: "Es también una regulación totalmente asimétrica en el trato que se otorga a los mercados regulados; mientras que por una parte es por fortuna muy puntual en las medidas que pueden imponerse a la telefonía, es muy limitada en el trato que en apariencia se impone a la televisión. Resulta notorio el interés de mantener los privilegios de los consorcios mediáticos". ${ }^{47}$ Pero no sólo eso, sino que promovía una regulación de preponderancia contraria al texto constitucional. Pretendía regular los mercados de telecomunicaciones y radiodifusión por sectores, de tal suerte que las declaratorias que en el futuro impusiera el IFT no se refirieran a estos servicios en su conjunto, lo cual permitiría una segmentación favorable a los intereses de los concesionarios. ${ }^{48}$

\footnotetext{
${ }^{47}$ Idem.

${ }^{48}$ Para la Amedi, también se intentaba imponer un esquema muy flexible para que un concesionario dejara de ser preponderante, desconociendo que el texto constitucional precisa que las medidas impuestas por el IFT se extinguirán en sus efectos cuando exista "competencia efectiva", no cuando un operador proponga disminuir su participación en el mercado por abajo de 50\%. Idem.
} 
$\mathrm{Al}$ respecto, en otro documento - difundido por la Amedi para convocar a la reunión del 11 de abril de 2014, donde se constituyó un Frente por la Comunicación Democrática conformado por políticos de varios partidos, académicos expertos en el tema, artistas e intelectuales —, ${ }^{49}$ los críticos de la iniciativa del presidente Enrique Peña Nieto sostenían que, tal como sucedió en "el primer intento derrotado por la Suprema Corte de Justicia en el año 2007, en ella se reincorporaban los beneficios a Televisa "con disposiciones a su medida para mantener su condición monopólica y [...] retrasar lo más posible una real competencia". ${ }^{50}$

Así, la ley propuesta por Enrique Peña Nieto beneficiaba a Televisa por dos vías. En la televisión abierta planteaba adjudicar automáticamente canales adicionales mediante disposiciones de multiprogramación, y en la televisión restringida o de paga había presentado una redacción "tramposa" que sustituía la palabra servicios por sectores a la hora de fijar la preponderancia de las empresas. ${ }^{51}$ Así, determinar la preponderancia de una empresa por sector (radiodifusión y telecomunicaciones) es más conveniente para los dueños de las concesiones de televisión que determinarla por servicios (radio, televisión abierta, de paga, telefonía fija, telefonía móvil, internet) porque hace difícil identificar detalladamente sus prácticas monopólicas. ${ }^{52}$

Por lo demás, la Amedi juzgaba que la iniciativa transgredía la disposición constitucional que prohíbe la suspensión de los actos reclamados dentro del juicio de amparo, al permitir que las multas no fueran exigibles hasta que la resolución causara estado tanto en el ámbito administrativo como en el judicial..$^{53}$ Otra crítica se relacionaba con el aplazamiento ilegal del llamado "apagón analógico" hasta 2017. Según la Amedi, tal retraso de dos años

\footnotetext{
${ }^{49}$ El Frente por la Comunicación Democrática fue formado a partir de la convocatoria suscrita por: Cuauhtémoc Cárdenas Solórzano, Javier Corral Jurado, Sergio Aguayo, Elisa Alanís, Alma Rosa Alva de la Selva, Clara Luz Álvarez, Virgilio Caballero, José Luis Caballero Ochoa, Manuel Camacho Solís, Purificación Carpinteyro, Carlos Castillo López, Tatiana Clouthier, Miguel Concha Malo, María Eugenia Chávez, Denise Dresser, Alejandro Encinas Rodríguez, Javier Esteinou, Alfredo Figueroa, Gael García Bernal, Víctor García Zapata, Daniel Gershenson, Daniel Giménez Cacho, José Harnández, Gonzalo Ibarra Torres, Clara Jusidman, Juan Sebastián Larrosa, Bernardo Masini Aguilera, Fabrizio Mejía Madrid, Guillermo Orozco, Aminadab Rafael Pérez Franco, Elena Poniatowska, Ricardo Raphael, Laura Rojas Hernández, Cristina Romo Gil, Ernesto Ruffo Appel, Verónica Sada Pérez, Layda Sansores, Javier Sicilia, Beatriz Solís Leree, Brisa Solís Ventura, Gabriel Sosa Plata, Mony de Swaam Addati, Fernando Turner Dávila, Esteban Volkov Bronstein, Olivia Zerón y Agustín Ramírez Ramírez (presidente de la Amedi). Asociación Mexicana de Derecho a la Información. [Consulta: 14 de junio, 2015]. Disponible en: http:// www.amedi.org.mx/prensa/comunicados/867-la-contrarreforma-en-telecomunicaciones-de-pena-nieto ${ }^{50}$ Idem.

${ }^{51}$ Idem.

${ }^{52} \mathrm{CNN}$, "20 puntos clave en las nuevas leyes sobre telecomunicaciones". [Consulta: 14 de junio, 2015]. Disponible en: http://mexico.cnn.com/nacional/2014/07/09/20-puntos-clave-en-las-nuevas-leyes-sobre-telecomunicaciones

${ }_{53}$ Asociación Mexicana de Derecho a la Información. [Consulta: 28 de junio, 2014]. Disponible en: http://www.amedi.org.mx/prensa/comunicados/869-cronica-de-un-despojo-los-derechos-fundamentales-en-la-iniciativa-de-ley-en-telecomunicaciones-y-radiodifusion
} 
resultaba contrario al texto constitucional. Además, al establecer el estándar de cumplimiento con un porcentaje de $90 \%$ de penetración, permitiría mantener la ocupación de la banda de los $700 \mathrm{MHz}$, con lo cual se incumplirían las medidas para democratizar el acceso a la banda ancha. ${ }^{54}$

Ante el Senado de la República, la Amedi expuso estas razones de su inconformidad hacia la iniciativa de ley secundaria en telecomunicaciones y radiodifusión enviada por el presidente Enrique Peña Nieto, ya que constituía un retroceso del marco regulatorio que podría diluir la reforma constitucional del 2013. Por ello, hizo un llamado a los legisladores miembros de las comisiones dictaminadoras de Comunicaciones y Transportes, de Radio, Televisión y Cinematografía, así como de Estudios Legislativos, a no olvidar el proyecto de ley que había entregado en octubre de ese año, y a su obligación legal y ética de analizar su contenido y contrastarlo con la iniciativa presidencial. ${ }^{55}$

El Frente por la Comunicación Democrática, constituido en gran medida por el activismo de la Amedi, detalló las contradicciones halladas entre la reforma ya aprobada constitucionalmente y la iniciativa presidencial de leyes secundarias. Sobre esa base, anunció que recurrirían a la Suprema Corte de Justicia de la Nación para que resolviera la inconstitucionalidad de la propuesta de Enrique Peña Nieto, en caso de ser aprobada. ${ }^{56}$ Sin embargo, la iniciativa presidencial fue aprobada sin mayores cambios y no fue posible revertir las leyes secundarias que echaban abajo muchos de los avances de la reforma constitucional en la materia.

\footnotetext{
${ }^{54}$ Idem.

${ }^{55} \mathrm{El}$ "Foro de análisis sobre las leyes secundarias en materia de telecomunicaciones y radiodifusión" se llevó a cabo los días 2, 3 y 4 de abril de 2014 en el Senado de la República convocado por las comisiones unidas de Comunicaciones y Transportes; Radio, Televisión y Cinematografia; y Estudios Legislativos. Senado de la República. [Consulta: 14 de noviembre, 2014]. Disponible en: http://comunicacion.senado. gob.mx/pdf/2014/abr/2014-04-02-programa.pdf

${ }^{56}$ Los integrantes del Frente por la Comunicación Democrática constituido el 11 de abril de 2014 firmaron un documento público en el cual se afirmaba lo siguiente acerca de la iniciativa presidencial: 1) Atenta en varias disposiciones contra los derechos fundamentales de libertad de expresión, libertad de información, acceso a las tecnologías de la información y la comunicación, privacidad de las comunicaciones, libertad de asociación. 2) La iniciativa presidencial no promueve una competencia efectiva en los servicios de radiodifusión. Deja intocado el duopolio de la televisión abierta, y le permite a Televisa seguir concentrando en la televisión de paga. 3) No desarrolla mecanismos efectivos y precisos para limitar la propiedad cruzada de los medios, ni medidas de desinversión. 4) Pretende invadir facultades del Instituto Federal de Telecomunicaciones que la Constitución le concede de manera exclusiva, como órgano autónomo encargado de otorgar las concesiones y responsable de la vigilancia de la transmisión de contenidos. Toda la iniciativa está trazada bajo un propósito de control gubernamental en el manejo de la información en medios de comunicación electrónica. 5) Ignora por completo los lineamientos establecidos en la reforma constitucional para impulsar un sistema de medios públicos democráticos, con independencia editorial y opciones de financiamiento. En los medios públicos y de uso social se encuentra el verdadero equilibrio y contrapeso al modelo mercantilista de la radiodifusión. 6) Invade esferas de la materia electoral y modifica aspectos del modelo de comunicación política. 7) Pospone la transición a la televisión digital terrestre, indispensable para la competencia y la pluralidad de la información. Asociación Mexicana de Derecho a la Información. [Consulta: 14 de junio, 2015]. Disponible en: http://www.amedi.org.mx/ prensa/comunicados/867-la-contrarreforma-en-telecomunicaciones-de-pena-nieto
} 


\section{Reflexiones finales}

Durante las dos últimas décadas del siglo xx se dieron dos procesos que cambiarían radicalmente la vida social en México. Por un lado, a partir de los años ochenta, el Estado transformó su papel en la economía y disminuyó su participación en muchos sectores, dejando vacíos en la sociedad que luego fueron ocupados por otros actores.

Junto a movimientos sociales con reivindicaciones específicas, surgieron asociaciones civiles creadas por grupos ciudadanos organizados en torno a una gran diversidad de temas y sin finalidades de lucro, por lo cual se ubicaron en el "tercer sector" de la sociedad. Algunos de ellos, asumidos ya plenamente como sociedad civil, se enfocaron en la lucha por espacios de libertad y derechos democráticos que no existían o sólo existían formalmente en el régimen autoritario encabezado por el PRI. La libertad de expresión y el derecho a la información eran sus demandas.

El derecho a la información, incluido en el artículo 6 de la Constitución en la reforma política de 1977 como necesario complemento a la garantía de libertad de expresión, era en realidad el único avance hasta que en 2013 se reformó estructuralmente el sector de las telecomunicaciones y la radiodifusión. La reforma constitucional es un enorme avance y sería un error dar por hecho que se debe solamente al Pacto por México. Es cierto que la reforma se concretó a la sombra de ese acuerdo de élites políticas, pero también lo es que la sociedad civil tiene un mérito incuestionable en ese avance, porque no ha regateado esfuerzos por obligar al Estado y a los empresarios de medios para que garanticen y respeten los derechos ciudadanos para el ejercicio de las libertades de expresión y de información. La Amedi y el movimiento \#YoSoy132 son protagonistas centrales de esta reforma.

La iniciativa de ley enviada por el presidente Enrique Peña Nieto al Senado de la República desvió en parte sustancial lo establecido constitucionalmente y planteó un dilema que no hubiera sido difícil de resolver a los representantes políticos: entre la presión de los actores económicos (que debió ser considerable) y la exigencia de la sociedad civil de que se respetaran las reformas constitucionales ya aprobadas, no debió quedar duda en la opción de aprobar leyes favorables para la sociedad. Al inclinarse frente a los poderes fácticos, en especial los concesionarios de la televisión, Enrique Peña Nieto puso entredicho su palabra y se jugó una porción de la legitimidad de su mandato.

$\mathrm{Al}$ estudiar el tema de las telecomunicaciones y la radiodifusión en México, resulta muy interesante observar la paradoja consistente en que los preceptos de libre competencia y rechazo a los monopolios, base del proyecto económico neoliberal, fueron abandonados por quienes implementaron ese modelo de desarrollo en el país. Por otro lado, fueron recogidos por la 
sociedad civil en su lucha contra la concentración en esas industrias, porque implica menor espacio para la pluralidad y por ello afecta la calidad del debate democrático. Al ceder ante los dueños de las concesiones con la imposición de leyes secundarias (las cuales constituyen un retroceso frente a los avances logrados en la reforma constitucional), el gobierno mostró que el proyecto neoliberal, al menos en estas industrias, incluye su práctica rendición frente a los poderes fácticos. 